\title{
ANALISIS SALURAN DAN MARGIN PEMASARAN MANGGIS STUDI KASUS DI KELOMPOK TANI MANGGISTA DESA CIBOKOR KECAMATAN CIBEBER KABUPATEN CIANJUR
}

\author{
Oleh : \\ Asep Saepul Alam**) \\ Agus Himawan Sutanto*)
}

\begin{abstract}
Abstrak
Salah satu Kecamatan yang menjadi sentra produksi Buah Manggis adalah Kecamatan Cibeber Kabupaten Cianjur. Penelitian dilakukan di Kelompok tani Manggista Desa Cibokor, Kecamatan Cibeber, Kabupaten Cianjur. Dimulai pada Bulan April sampai dengan Juli 2019 dengan tujuan untuk : 1) Untuk mengetahui pola saluran pemasaran Buah Manggis Kelompok Tani Manggista Desa Cibokor, Kecamatan Cibeber, Kabupaten Cianjur. 2) Untuk mengetahui besar margin pemasaran Buah Manggis untuk masing-masing saluran pemasaran. Penelitian ini menggunakan teknik purposive sampling dan snowball sampling dalam penentuan tempat dan responden. Hasil penelitian menunjukkan bahwa : 1. Pola saluran pemasaran buah manggis di Kelompok Tani Manggista, yakni : 1). Kelompok tani Manggista $\rightarrow$ pengepul $\rightarrow$ konsumen, 2). Kelompok tani Manggista $\rightarrow$ pengepul $\rightarrow$ pengecer $\rightarrow$ konsumen (Bogor). 2. Besar margin pada saluran pemasaran I sebesar Rp.2.000-, besar margin pada saluran pemsaran II sebesar Rp.7.400-,. Diketahui untuk pemasaran buah Mangis memiliki R/C sebesar 1,81,didapatkan dari Harga jual sebesar Rp.12,400 dibagi dengan jumlah biaya pemasaran yaitu Rp.6.850 maka di dapatkan Nilai R/C ratio sebesar 1.81. Sedangkan Farmer's share yang paling efisien berada di saluran pemasaran I yaitu 71,45\%.
\end{abstract}

Kata Kunci : Buah Manggis, Pola Saluran Pemasaran, Margin Pemasaran, R/C Ratio dan Farmer's Share.

\begin{abstract}
One of the subdistricts that are the centers of the production of the Mangosteen Fruit is Cibeber District, Cianjur Regency. The study was conducted at the Manggista Farmer Group in Cibokor Village, Cibeber District, Cianjur Regency. Starting in April until July 2019 with the aim to: 1) To find out the marketing channel pattern of Mangosteen Fruit Manggista Farmer Group Cibokor Village, Cibeber District, Cianjur Regency. 2) To find out the marketing margin of Mangosteen Fruit for each marketing channel. This research uses purposive sampling and snowball sampling techniques in determining the place and respondent. The results showed that: 1. The marketing channel pattern of mangosteen fruit in the Manggista Farmer Group, namely: 1). Manggista farmer groups $\rightarrow$ collectors $\rightarrow$ consumers, 2). Manggista farmers group $\rightarrow$ collectors $\rightarrow$ retailers $\rightarrow$ consumers. 2. The margin on marketing channel I is Rp.1,600-, the margin on the marketing channel II is Rp.7,400-,. It is known that for marketing Mangis fruit has an R / C of 1.81, obtained from the selling price of Rp.12,400 divided by the total marketing cost of Rp.6,850 then the R / C ratio value of 1.81 is obtained. Whereas the most efficient Farmer's share was in marketing channel I which was $77.14 \%$.
\end{abstract}

Keywords: Mangosteen, Marketing Channel Pattern, Marketing Margin, R / C Ratio and Farmer's Share.

*) Alumni Fakultas Sains Terapan UNSUR

**) Dosen Fakultas Sains Terapan UNSUR 


\section{PENDAHULUAN}

Manggis (Garcinia mangostana Linn) merupakan salah satu tanaman buah asli Indonesia yang mempunyai potensi ekspor sangat besar. Tanaman ini mendapat julukan ratunya buah (queen of fruit) karena keistimewaan dan kelezatannya (Anonim 2006). Manggis menyimpan berbagai manfaat yang luar biasa bagi kesehatan atau biasa disebut sebagai pangan fungsional (functional food). Potensi dan peluang pasar manggis sangat besar karena banyaknya permintaan global. Manfaat dari buah manggis ini di dalam negeri sendiri belum dikenal oleh masyarakat. Buah manggis yang cukup memiliki potensi, saat ini dikelola dengan sangat sederhana. Beberapa Negara sudah sejak lama manggis dijadikan sebagai obat dan bahan terapi, terutama bagian kulitnya (Permana, 2010). Volume ekspor manggis menempati urutan pertama dari seluruh ekspor buah segar Indonesia, meningkat dari 4.473 ton pada tahun 1999 menjadi 9.621 ton pada tahun 2004 (Deptan, 2005) dengan pasar ke Taiwan, Eropa, Hongkong, Timur tengah, Singapura dan Jepang.

Permasalahan penting yang dihadapi pengekspor manggis adalah ketidakmampuan untuk memenuhi kuantitas dan kontinuitas permintaan dari negara pengimpor. Dari segi kuantitas, hanya sekitar $17 \%$ dari jumlah total buah manggis Indonesia yang dapat diekspor di antaranya, karena adanya getah kuning, serangan hama, penyakit kulit, buah mengeras dan lain-lain. Dari segi kontinuitas, penyebabnya adalah sifat manggis yang berbuah musiman sehingga suplainya hanya terjamin dalam beberapa bulan dalam setahun. Panen manggis di Indonesia berlangsung pada DesemberApril dengan puncak produksi pada Pebruari-Maret. Di luar musim panen tersebut, praktis buah manggis tidak berada di pasaran.

Tumbuhan manggis tersebar luas di Indonesia, baik di habitat alami maupun yang dibudidayakan, tumbuhan ini dapat ditemukan sampai ketinggian 600 meter di atas permukaan laut dengan suhu rata-rata $20-30^{\circ} \mathrm{C}$ (Mardiana, 2011).

Cianjur merupakan salah satu sentra produksi manggis, untuk memenuhi peluang terhadap tingginya permintaan manggis baik untuk pasar domestik maupun ekspor dalam upaya mewujudkan manggis sebagai buah primadona ekspor, pemerintah. Kabupaten Cianjur telah mengembangkan areal tanaman manggis secara bertahap. Menurut (BPP) Cibeber Pada tahun 1992 telah dikembangkan kebun manggis $(10,000)$ pohon yang tersebar di Kecamatan Cibeber. Kecamatan Cibeber merupakan salah satu kecamatan yang berada di wilayah Kabupaten Cianjur. Kecamatan Cibeber ini mempunyai luas wilayah $90,30 \mathrm{~km}^{2}$ dengan topografinya bervariasi terdiri dari $75 \%$ perbukitan dan $25 \%$ daratan.

Margin pemasaran merupakan perbedaan antara harga yang dibayarkan oleh konsumen dengan harga yang diterima oleh peani atau merupakan biaya dari jasa-jasa pemasaran yang dibutuhkan sebagai akibat dari permintaan dan jasa pemasaran. Semakin besar perbedaan harga antara lembaga-lembaga tataniaga yang terlibat, terutama antara harga yang terjadi ditingkat eceran dengan harga yang diterima peani. Maka semakin besar pula margin tataniaga dari komoditi yang bersangkutan. Halini disebabkan banyaknya lembaga tataniaga yang terlibat mengakibatkan biaya tataniaga meningkat, yang akan diikuti peningkatan pengambilan keuntungan oleh setiap lembaga tataniaga yang terlbat ( Sudiyono,A. 2001).

\section{METODE PENELITIAN}

Penelitian dilakukan di Kelompok Tani Manggista Desa Cibokor Kecamatan Cibeber Kabupaten Cianjur. Pemilihan lokasi dilakukan secara sengaja (purposive), dengan pertimbangan bahwa Kelompok Tani Manggista merupakan salah satu lembaga yang melakukan pemasaran buah 
manggis. Penelitian ini dilaksanakan dari bulan April sampai dengan Juli 2019.

Jenis data dan Sumber data yang digunakan dalam penelitian ini adalah data primer dan data sekunder. Data data primer diperoleh langsung di lapang melalui responden yaitu distributor dan data lainnya diperoleh melalui observasi dan wawancara kepada pemiliknya dan pegawai. Pengumpulan data primer dalam penelitian ini melalui cara observasi, menyebarkan kuesioner dan melakukan wawancara secara langsung yang telah disiapkan sebelumnya kepada responden secara langsung sedangkan, sumber data sekunder Sumber yang tidak langsung memberikan data kepada pengumpul data, misalnya lewat orang lain atau lewat dokumen, Data sekunder diperoleh dari berbagai literatur-literatur yang dapat menunjang penelitian yang ada kaitannya dengan penelitian ini.

Analisis dalam penelitian ini yaitu Analisis Data primer dan data skunder tentang aspek petani selaku pembudidaya dan pelaku pemasaran manggis ini dianalisis dengan menggunakan analisis statistik deskriptif, yaitu analisis yang berupaya untuk memperoleh gambaran yang lengkap dan akurat dari situasi di lapangan.

Desain formal diperlukan untuk mencegah di kumpulkannya data yang tidak perlu, analisis deskriptif ini dituangkan dapat berupa tabel, gambar, kurva dan lain sebagainya.

\section{Analisis Saluran Pemasaran}

Saluran pemasaran adalah serangkaian organisasi yang terkait dalam proses menjadikan suatu produk siap untuk di konsumsi oleh konsumen, saluran pemasaran ini di teliti mulai dari petani produsen hingga komsumen akhir di sekitar daerah Kecamatan Cibeber, semakin panjang pemasarannya maka pada umumnya tidak efisien, hal ini dikarenakan margin yang terbentuk antara produsen dan komsemen semakin besar.

\section{Analisis Harga}

Analisis ini digunakan untuk mengetahui sistem penentuan harga yang terjadi di tingkat petani, tingkat pedagang pengumpul dan pada tingkat pedagang pengecer.

Dimana :

$$
\mathrm{Mm} \quad=\mathrm{Pe}-\mathrm{Pf}
$$

$\mathrm{Mm}=$ margin pemasaran tingkat petani $\mathrm{Pe}=$ harga ditingkat kelembagaan pemasaran tujuan pemasaran dari petani $\mathrm{Pf}=$ harga dari tingkat petani

\section{Analisis Margin Pemasaran}

Margin pemasaran menurut Limbong sitorus, Dalam Sudiyono (2011). Dapat diartikan sebagai perbedaan harga yang diterima produsen, margin pemasaran dapat dinyatakan sebagai nilai dari jasa-jasa pelaksanaan kegiatan dari sejak kegiatan produsen sampai tingkat konsumen dan keuntungan diambil oleh setiap pelaku pemasaran.

Untuk menganalisis margin pemasaran dalam penelitian ini, data harga yang digunakan adakah harga ditingkat lembaga pemasaran, sehingga dalam perhitungan margin pemasaraan digunakan rumus :

$$
\mathrm{Mmi}=\mathrm{Ps}-\mathrm{Pb}
$$

Dimana :

Mmi = Margin pemasaran pada setiap lembaga pemasaran

Ps = Harga jual pada setiap tingkat lembaga pemasaran

$\mathrm{Pb}=$ Harga beli pada setiap tingkat lembaga pemasaran

\section{Farmer'r share}

Analisis digunakan untuk melihat bagian harga yang diterima oleh petani secara sistematis, Farmer's share dapat dirumuskan sebagai berikut:

$$
\mathrm{Fs}=\frac{\mathrm{Hp}}{\mathrm{He}} \times 100 \%
$$

Dimana :

Fs = bagian harga yang diterima

petani farmer's share (\%)

$\mathrm{Hp}=$ harga ditingkat produsen

$(\mathrm{Rp} / \mathrm{Kg})$

$\mathrm{He}=$ harga tingkat eceran $(\mathrm{Rp} / \mathrm{Kg})$ 
Tabel 1 Operasional Variabel.

\begin{tabular}{clcc}
\hline Variabel & \multicolumn{1}{c}{ Konsep Variabel } & Indikator & Skala \\
\hline \multirow{2}{*}{ Analisis } & Saluran pemasaran adalah organisasi yang & & \\
Saluran & saling tergantung yang tercakup dalam & & \\
pemasaran & proses yang membuat produk atau jasa & Pola saluran pemasaran & Ordinal \\
& $\begin{array}{l}\text { menjadi tersedia untuk digunakan atau } \\
\text { dikonsumsi. Kotler dan keller (2007). }\end{array}$ & & \\
Analisis & Margin pemasaran merupakan rasio antara & Margin dan keuntungan & \\
Margin & nilai tambah yang diperoleh pelaku & biaya (R/C) & Ratio \\
Pemasaran & $\begin{array}{l}\text { pemasaran tertentu dan harga yang } \\
\text { dibayarkan oleh konsumen. (Khol 2004). }\end{array}$ & Analisis Farmer's share & \\
\hline
\end{tabular}

\section{HASIL DAN PEMBAHASAN}

\section{Karakteristik responden}

Tabel 2. Karakteristik Responden Berdasarkan Jenis Kelamin

\begin{tabular}{cccc}
\hline No & Uraian & Jumlah & Presentase $\%$ \\
\hline 1 & Laki-laki & 20 & 100 \\
2 & Perempuan & 0 & 0 \\
& Jumlah & 20 & 100 \\
\hline
\end{tabular}

Sumber, Data Primer (Diolah), 2019.

Berdasarkan Tabel 2. diketahui bahwa seluruh responden berjenis kelamin laki-laki. Menurut hasil wawancara dengan Ketua Kelompok Tani bahwa anggota yang tergabung semuanya berjenis kelamin laki - laki disebabkan karena yang mengolah atau yang melaksanakan usahatani manggis adalah laki - laki sebagai kepala keluarga.

Tabel 3 . Responden Berdasarkan Usia.

\begin{tabular}{cccc}
\hline NO & Uraian & Jumlah & Presentase $\%$ \\
\hline 1 & $<25$ Tahun & 0 & 0 \\
2 & $26-35$ tahun & 2 & 10 \\
3 & 36-45 tahun & 7 & 35 \\
4 & $>46$ tahun & 11 & 55 \\
\hline & Jumlah & $\mathbf{2 0}$ & $\mathbf{1 0 0}$ \\
\hline
\end{tabular}

Sumber, Data Primer (Diolah),2019.

Berdasarkan pada tabel 3. di atas dapat diketahui bahwa dari 20 orang yang tergabung dalam Kelompok Tani manggista sebanyak $10 \%$ berada pada rentang usia 26 - 35 tahun, 35\% berada pada renta usia 36-45 tahun serta 55\% berada di atas usia lebih dari 46 tahun. dat ini menunjukan bahwa kebanyakan yang memiliki lahan dan pohon maggis di dominasi olah usia 46 tahun ke atas.

Tabel 4. Responden Berdasarkan Pendidikan.

\begin{tabular}{cccc}
\hline No & Uraian & Jumlah & Presentase $\%$ \\
\hline 1 & SD & 15 & 75 \\
2 & SMP & 3 & 15 \\
3 & SMA & 2 & 10 \\
4 & Sarjana & 0 & 0 \\
\hline & Jumlah & $\mathbf{2 0}$ & $\mathbf{1 0 0}$ \\
\hline
\end{tabular}

Sumber, Data Primer (Diolah),2019.

Berdasarkan Tabel 4. diketahui bahwa mayoritas responden adalah tingkat pendidikan terakhirnya adalah sekolah dasar yaitu $75 \%$, hal ini tentu memberikan dampak terhadap pengetahuan yang didapat oleh petani tersebut, akan tetapi 
mengenai usahatani petani mendapatkan bimbingan serta pengawasan dari petugas pertanian yang disebut dengan petugas penyuluh pertanian yang bertugas di Desa Cibokor.

Tabel 5. Tabel Responden Berdasarkan Pendapatan.

\begin{tabular}{cccc}
\hline No & Uraian & Jumlah & Presentase $\%$ \\
\hline 1 & $<1$ juta & 0 & 0 \\
2 & $1-2$ juta & 9 & 45 \\
3 & $2-3$ juta & 9 & 45 \\
4 & $>3$ juta & 2 & 10 \\
\hline & Jumlah & $\mathbf{2 0}$ & $\mathbf{1 0 0}$
\end{tabular}

Sumber, Data Primer (Diolah),2019.

Berdasarkan tabel 5. yaitu pendapatan perbulan pada petani tersebut yaitu $45 \%$ memiliki pendapatan perbulan sebesar 1-2 juta, 45\% 2-3 juta dan 10\% di

Tabel 6. Responden Berdasarkan Luas Lahan.

\begin{tabular}{cccc}
\hline No & luas lahan $(\mathrm{Ha})$ & Jumlah & Presentase $\%$ \\
\hline 1 & $<0,5$ & 12 & 60 \\
2 & $0,5-1$ & 6 & 30 \\
3 & $1-1,5$ & 2 & 10 \\
\hline & Jumlah & $\mathbf{2 0}$ & $\mathbf{1 0 0}$
\end{tabular}

Sumber, Data Primer (Diolah) 2019.

Berdasarkan status kepemilikan lahan yakni jumlah keseluruhan petani yang berjumlah 20 orang, persentase petani yang memiliki lahan $<0,5 \mathrm{Ha}$ yakni $60 \%$, sementara presentase status kepemilikan lahan 0,5-1 Ha berkisar 30\%, status kepemilikan lahan dari luas lahan 11,5 Ha berkisar 10\% dapat dilihat bahwa status kepemilikan lahan yang terbesar adalah luas lahan $<0,5 \mathrm{Ha}$ yakni presentasenya berkisar $60 \%$, jumlah petani pemilik mendominasi karena status kepemilikan lahan yang dipunyai petani adalah lahan yang diberikan orang tuanya secara turun temurun. tasat 3 juta. Data ini menunjukan bahwa pendapatan di kelompok tani tersebut belum mencapai hasil yang maksimal.

\section{Analisis Usahatani di Kelompok Tani Manggista}

Analisis mengenai struktur biaya usahatani merupakan jenis dan besarnya biaya yang harus dipikul oleh seorang petani yang melakukan usahatani dalam rangka memproduksi sampai menjualnya. Struktur biaya dalam usahatani mangis dapat diketahui bahwa ada biaya tetap dan ada biaya variabel. Selain biaya ada juga pendapatan dari penerimaan usahatani setelah dilakukannya penjualan manggis dari hasil usahatani tersebut, Setelah mendapatkan penerimaan usaha tani maka dapat dihitung $\mathrm{R} / \mathrm{C}$ rasio agar mengetahui layak atau tidaknya usaha tani varietas Pandanwangi ini di jalankan. 


\section{Biaya Usahatani Manggis di Kelompok Tani Manggista}

Tabel 7. Struktur Rata-rata Biaya Tetap Usahatani Manggis dalam $4500 \mathrm{~m}^{2}$.

\begin{tabular}{|c|c|c|c|c|c|c|}
\hline No & $\begin{array}{c}\text { Jenis Biaya } \\
\text { Tetap }\end{array}$ & volume & Satuan & $\begin{array}{c}\text { biaya Satuan } \\
(\mathrm{Rp})\end{array}$ & $\begin{array}{c}\text { Jumlah } \\
\text { (Rp) }\end{array}$ & $\begin{array}{c}\text { Presentase } \\
(\%)\end{array}$ \\
\hline 1 & Pajak & 4500 & $\mathrm{M}^{2}$ & 67.200 & 67.200 & 3,35 \\
\hline 2 & Bibit & 52 & Pohon & 21.000 & 1.092 .000 & 54,49 \\
\hline 3 & Penanaman & & & 50.000 & 50.000 & 2,49 \\
\hline 4 & persiapan lahan & 4500 & $\mathrm{M}^{2}$ & 515.000 & 515.000 & 25,70 \\
\hline 4 & Keranjang & 1 & Buah & 40.000 & 40.000 & 2,00 \\
\hline 5 & Alat-alat: & & & & & \\
\hline & a. parang & 1 & buah & 40.000 & 40.000 & 2,00 \\
\hline & b. garpu & 1 & buah & 120.000 & 120.000 & 5,99 \\
\hline & c. cangkul & 1 & buah & 80.000 & 80.000 & 3,99 \\
\hline \multicolumn{5}{|c|}{ Jumlah Biaya tetap } & 2.004 .200 & 100,00 \\
\hline
\end{tabular}

Sumber, Data Primer (Diolah) 2019.

Sebagaimana diuraikan dalam Tabel 7. di atas diketahui bahwa struktur biaya tetap usahatani Buah Manggis terdiri dari biaya tetap untuk pajak, bibit, persiapan lahan, keranjang dan alat - alat. Dimana biaya tetap tertinggi terdapat pada Pembelian Bibit yang mencapai 54,49\% sedangkan yang terendah terdapat pada biaya pembelian parang yang hanya $2,00 \%$.

Tabel 8. Struktur rata-rata Biaya variabel Usahatani Manggis Permusim dalam 4500M².

\begin{tabular}{lllllll}
\hline No & $\begin{array}{c}\text { Jenis Biaya } \\
\text { Variabel }\end{array}$ & volume & satuan & $\begin{array}{c}\text { biaya satuan } \\
\text { (RP) }\end{array}$ & $\begin{array}{c}\text { Jumlah } \\
\text { (Rp) }\end{array}$ & $\begin{array}{c}\text { Presentase } \\
(\mathbf{\%})\end{array}$ \\
\hline 1 & Pupuk Kandang & 158 & $\mathrm{~kg}$ & 1.000 & 158.000 & 5,49 \\
2 & Pestisida & 2 & botol & 55.000 & 110.000 & 3,82 \\
3 & Tenaga kerja & & & & & \\
4 & Pemupukan & 2 & HOK & 50.000 & 100.000 & 3,47 \\
5 & Penyemprotan & 1 & HOK & 50.000 & 50.000 & 1,74 \\
6 & Panen & 1640 & $\mathrm{~kg}$ & 1.500 & 2.460 .000 & 85,48 \\
Jumlah Biaya Variabel & & & & 2.878 .000 & 100 \\
\hline
\end{tabular}

Sumber, Data Primer (Diolah) 2019.

Penjelasan pada hasil penelitian ini diperoleh bahwa struktur biaya variabel terbesar adalah biaya panen yang mencapai 85,48\%. Sedangkan struktur biaya terkecil terdapat pada penyemprotan yaitu hanya $1,74 \%$.

Tabel 9. Total Biaya Buah Manggis dalam $4500 \mathrm{~m}^{2}$.

\begin{tabular}{cccc}
\hline No & Uraian & Nilai & \% \\
\hline 1 & Biaya tetap & 2.004 .200 & 41,05 \\
2 & Biaya variabel & 2.878 .000 & 58,95 \\
\hline & Jumlah & $\mathbf{4 . 8 8 2 . 2 0 0}$ & $\mathbf{1 0 0}$ \\
\hline
\end{tabular}

Sumber, Data Primer (Diolah) 2019.

Berdasarkan Tabel 4.8 di atas diketahui bahwa biaya total tertinggi terdapat pada biaya variabel yang mencapai 58,95\% sedangkan pada biaya tetap mencapai $41,05 \%$.
Penerimaan usaha tani manggis di kelompok tani Mangista

Penerimaan usahatani ini dihitung berdasarkan hasil penjualan Buah manggis, kemudian dikalikan dengan harga satuan Buah manggis. Adapun rincian mengenai penerimaan usahatani Buah manggis adalah sebagai berikut. 
Tabel 10. Penerimaan Usahatani Buah manggis di Kelompok Tani Manggista dalam 4500M².

\begin{tabular}{rrrrr}
\hline No & uraian & Volume (Kg) & harga Satuan (Rp) & Jumlah (Rp) \\
\hline 1 & Manggis & 1.640 & 5.400 & 8.856 .000 \\
\hline
\end{tabular}

Dari data Tabel 10. bahwa Ratarata dari setiap orang dari anggota kelompok tani menghasilkan $1.640 \mathrm{~kg}$ buah manggis. Di kalikan dengan rata-rata jumlah dipegecer yaitu Rp.5.400-, jadi rata-rata tiap orangnya memiliki pendapatan 8.856.000 per musimnya.
Adapun R/C rasio untuk petani yaitu : jumlah pendapatan sebesar Rp.8.856.000,di bagi dengan total biaya variabel dan total biaya tetap yaitu sebesar Rp.4.882.200,- sehingga di peroleh R/C racio sebesar 1,81. Sehingga dengan hasil $\mathrm{R} / \mathrm{C}$ racio 1,81 menyatakan bahwa usaha buah tani ini layak untuk di lanjutkan.

Tabel 11. Marjin dan R/C Ratio pemasaran Buah Manggis.

\begin{tabular}{|c|c|c|}
\hline \multirow{3}{*}{ Jenis kegiatan } & \multicolumn{2}{|c|}{ Saluran pemasaran } \\
\hline & (I) Satu tingkat & (II) Dua tingkat \\
\hline & Nilai (Rp./Kg) & Nilai (Rp./kg) \\
\hline \multicolumn{3}{|l|}{ Petani } \\
\hline Harga Jual & 5.400 & 5.400 \\
\hline \multicolumn{3}{|l|}{ Pengepul/Pedagang besar } \\
\hline Harga beli & & 5.400 \\
\hline Transportasi & & 100 \\
\hline Bongkar muat & & 50 \\
\hline Biaya kemasan & & 0 \\
\hline Jumlah biaya pemasaran & & 5.550 \\
\hline Harga Jual & & 6.500 \\
\hline Margin Pemasaran & & 1.100 \\
\hline Keuntungan pemasaran & & 950 \\
\hline $\mathrm{R} / \mathrm{C}$ Ratio & & 1,17 \\
\hline \multicolumn{3}{|l|}{ Pengecer } \\
\hline Harga Beli & 5.400 & 6.500 \\
\hline Transportasi & 100 & 200 \\
\hline Bongkar muat & 50 & 50 \\
\hline kantong plastik & 100 & 100 \\
\hline Jumlah biaya pemasaran & 5.650 & 6.850 \\
\hline Harga jual & 7.000 & 12.400 \\
\hline Margin pemasaran & 1.600 & 5.900 \\
\hline Keuntungan pemasaran & 1.350 & 5.550 \\
\hline $\mathrm{R} / \mathrm{C}$ ratio & 1,24 & 1,81 \\
\hline Harga masing-masing di tingkat & $\mathrm{I}$ & II \\
\hline \multicolumn{3}{|l|}{ Lembaga Pemasaran } \\
\hline Harga ditingkat konsumen & 7.000 & 12.400 \\
\hline Margin & 1.600 & 7.000 \\
\hline
\end{tabular}

Sumber, Data Primer (Diolah)2019.

Pada tabel 11. saluran pemasaran satu tingkat (saluran pemasaran I) jumlah biaya pemasaran sebesar Rp.5.650 / kg total marjin pemasaran Rp.1.600 / kg dan total keuntungan pemasaran sebesar Rp.1.350 / kg.Hal ini pengepul/pedagang besar dan melakukan fungsi pemasaran sebelum Buah Manggis dijual pada konsumen. Dalam hal ini pengepul bisa di katakan juga sebagai pengecer.

Pada tabel 4.10 saluran pemasaran dua tingkat ( saluran pemasaran II) jumlah biaya pemasaran sebesar Rp. $5.550 / \mathrm{kg}$, total margin pemasaran $\mathrm{Rp}$. 
$1.100 / \mathrm{kg}$ dan total keuntungan pemasaran sebesar Rp 950 /kg. Pada saluran pemasaran ini pengepul/pedagang besar mendapatkan keuntungan pemasaran lebih sedikit pada (saluran pemasaran ke II) sebesar $950 / \mathrm{kg}$ lebih kecil dari (saluran pemasaran I) karena pengepul menjual terlebih dahulu Buah manggisnya ke Pengecer sebelum ke konsumen.

Pada tabel 11. menunjukkan bahwa saluran pemasaran untuk pengecer (saluran pemasaran II) biaya pemasaran yang dikeluarkan sebesar Rp $6.850 / \mathrm{kg}$, dengan total marjin pemasaran sebesar Rp. $5.900 / \mathrm{kg}$, dan total keuntungan pemasaran sebesar Rp. $5.550 / \mathrm{kg}$

Untuk mengetahui efisiensi dari saluran pemasaran Buah Manggis di Kelompok Tani Manggista, maka dapat dilihat dari keuntungan dan nilai $\mathrm{R} / \mathrm{C}$ ratio.

Pada tabel 11. dapat dilihat bahwa saluran pemasaran dua tingkat (saluran pemasaran II) merupakan saluran pemasaran yang lebih menguntungan untuk pengecer karena memiliki total keuntungan sebesar Rp. $5.550 \quad / \mathrm{kg}$ dengan besar R/C Ratio sebesar 1,81 sehingga angka tersebut menunjukan bahwa usaha ini layak.

Berdasarkan tabel 11. dapat dilihat bahwa saluran pemasaran satu tingkat (saluran pemasaran I) merupakan saluran pemasaran yang lebih sedikit mendapatkan total keuntungannya yaitu sebesar Rp. 1350,- per kilo gram dengan besar R/C Ratio sebesar 1,24 walaupun keuntungannya lebih kecil dari (saluran pemasaran II) usaha ini tetap layak untuk dijalankan karena $\mathrm{R} / \mathrm{C}$ ratio $>1$.
Berdasarkan penjelasan di atas nilai keuntungan dan $\mathrm{R} / \mathrm{C}$ ratio yang lebih besar terdapat di saluran pemasaran dua tingkat (saluran pemasaran II). karena berdasarkan hasil wawancaara pengecer pemasaran dua tingkat (Saluran pemasaran II) lebih efisien dengan permintaan pasar yang jauh lebih tinggi dibandingkan dengan pemasaran satu tingkat (saluran pemasaran I) mengingat hasil buah manggis memiliki batas waktu tertentu maka diperlukan perputaran barang yang lebih cepat dan itu ada di saluran pemasaran II.

\section{Farmer's Share}

Kriteria yang digunakan untuk mengetahui bahwa suatu pemasaran diangap efesien adalah tiap-tiap saluran pemasaran mempunyai nila margin pemasaran yang rendah dan mempunyai nilai presentase bagian yang diterima petani (farmer's share) tinggi. Suatu usaha secara nominal dikatakan bisa dilanjutkan apabila tidak mengalami kerugian atau usaha tersebut impas. Bila bagian harga yang diterima petani $<50 \%$ berarti belum efesien, bila bagian yang di terima petani $>50 \%$ maka pemasaran dikatakan efesien (sudiyono, 2002).

Farmer's Share adalah persentase perbandingan antara bagian harga yang diterima oleh petani dengan bagian harga yang diterima oleh konsumen akhir. Farmer's Share pada saluran pemasaran Buah Mangis di Kelompok Tani Manggista Desa Cibokor Kecamatan Cibeber Kabupaten Cianjur disajikan dalam tabel 12.

Tabel 12. Farmer's Share Pada Saluran Pemasaran Buah Manggis di Kelompok Tani Manggista.

\begin{tabular}{cccc}
\hline Saluran Pemasaran & $\begin{array}{c}\text { Harga di tingkat petani } \\
(\mathbf{R p )}\end{array}$ & $\begin{array}{c}\text { Harga di tingkat } \\
\text { Konsumen (Rp) }\end{array}$ & $\begin{array}{c}\text { Farmer's } \\
\text { Share }\end{array}$ \\
\hline Saluran pemasaran 1 & 5.400 & 7.000 & 77,14 \\
Saluran Pemasaran 2 & 5.400 & 12.400 & 43,55 \\
\hline
\end{tabular}

Sumber, Data Primer (Diolah) 2019. 
Pada tabel 12. Farmer's Share pada saluran pemasaran 1 mendapatkan bagian sebesar $77,14 \%$, saluran pemasaran 2 mendapatkan bagian 43,55\% bagian petani yang paling besar berada di saluran pemasaran satu tingkat (saluran pemasaran 1) yaitu sebesar $77,14 \%$. Pada saluran pemasaran 1 di katakan efesien Karena bagian harga yang diterima petani $>50 \%$. selain petani yang diuntungkan konsumen juga mendapatkan harga yang lebih murah dengan harga yang harus dibayarkan konsumen sebesar $7.000 / \mathrm{kg}$.

\section{KESIMPULAN}

Berdasarkan hasil dan pembahasan yang telah dijelaskan pada pembahasan sebelumnya, maka peneliti menyimpulkan beberapa hal sebagai berikut :

1. Pola saluran pemasaran Buah Mnaggis di kelompok tani Manggista terdapat 2 (dua) saluran pemasaran. Saluran pertama yaitu saluran pemasaran satu tingkat (Kelompok tani mangistapengepul - konsumen), saluran kedua yaitu saluran pemasaran dua tingkat (Kelompok tani Manggista - Pengepul - Pengecer - konsumen).

2. Besar margin pada saluran pemasaran I yaitu sebesar Rp.1.600-, besar margin pada saluran pemasaran II sebsar R.7.000,-. Saluran pemasaran yang efisien adalah saluran pemasaran I meskipun nilai margin keuntungannya lebih kecil dari saluran pemasaran II. Ini dikarenakan saluran pemasaran I memiliki margin yang relatip kecil dan jumlah harga yang di bayarkan kinsumen relatif lebih murah, dan Farmer's share yang paling efisien berada di saluran pemasaran I yaitu $77,14 \%$.

\section{DAFTAR PUSTAKA}

Anonim, 2006, Pedoman Penggunaan Obat Bebas dan Obat Bebas terbatas, Direktorat Bina Farmasis Komunitas dan Klinik Direktorat Jendral Bina Kefarmasian dan Alat Kesehatan Depkes RI.

Departemen Pertanian(Deptan). 2005. Lalat Buah (Bactrocera dorsalis).

Hartanto. 2011. Sukses Besar Budidaya Kelapa Sawit. Cetakan I.Yogyakarta: Citra Media Publishing.

Limbong dan Sitorus dalam Sudiyono, 2011. Analisis Efisiensi Pemasaran. - Fakultas Pertanian. Institut Pertanian Bogor. Bogor.

Mardiana, 2011, Ramuan dan Khasiat Kulit Manggis, Penebar Swadaya, Jakarta, 9, 15-18.

Nazaruddin. 1994. Sukun dan Keluwih. Penebar Swadaya.Jakarta.

Permana, (2010). Pendidikan Lingkungan Sosial Budaya dan Teknologi. Bandung: UPIPRESS.

SADI-ACIAR. (2009). Laporan Akhir: Rantai Nilai Sayuran di Kawasan Timur Indonesia - fokus pada cabe. Canberra: ACIAR.

Sudiyono, 2002. Pemasaran Pertanian, Farmer's Share. Universitas Muhamadiyah Malang. Malang.

Sudiyono, A. 2001. Pemasaran Pertanian. Universitas Muhamadiyah Malang. Malang.

YunitaSari. AnalisisFaktor-faktor Yang Mempengaruhi Keberhasilan Usaha Pedagang Kaki Lima Di GALABO(Gladag Langen Bogan) Solo Tahun 2011.Skripsi-1 Progdi Ilmu Ekonomi Studi Pembangunan. Surakarta: Fakultas Ekonomi UMS. 